\title{
$\mathrm{SNS}$ 를 이용한 패션업체의 마케팅 실태 연구 \\ -Facebook을 중심으로-
}

\author{
김태진 ${ }^{1}$, 진성아 ${ }^{1^{*}}$ \\ ${ }^{1}$ 성결대학교 멀티미디어공학부
}

\section{A Study on the State of Fashion Marketing Using the SNS -Focused on the Facebook-}

\author{
Taejin Kim $^{1}$ and Seongah Chin $^{1^{*}}$ \\ ${ }^{1}$ Division of Multimedia Engineering, Sungkyul University
}

\begin{abstract}
요 약 시대의 변화에 따른 IT 기술의 급속한 발전은 전반적인 산업영역에서 예전보다 쉽게 정보를 취득하고 가공 할 수 있는 여건을 형성하고 있다. 최근 각광 받고 있는 SNS의 변화를 살펴보면 스마트폰 이용이 대중화되면서 마케 팅 툴로서의 가치가 더욱 급부상하고 있다. 본 연구는 패션 마케팅 분야에서 새로운 시장으로 떠오르고 있는 Facebook 활용 사례를 연구하였다. 패션업체 10 곳을 선정하여 활동지표의 기준이 되는 '게시글', 'like this', 'people talking about this' '이벤트'를 중심으로 페이스북 페이지를 연구하였고 spearman 순위 상관계수를 이용하여 위 지표들 간의 상관분석을 실시하였다. 연구 결과 '게시글'과 'like this'의 관계는 높은 상관관계를 보여 주었고 다른 요인들 사이에 서는 상관관계를 확인할 수 없었다. 페이스북 페이지를 이용한 마케팅은 소비자와 업체와의 소통이 기존 매체에 비해 원활하였는데 이는 SNS의 마케팅의 이용이 기존의 마케팅의 한계였던 소통의 벽을 넘을 수 있음을 보여주는 결과였다.
\end{abstract}

\begin{abstract}
Rapid evolutions in recent years related to IT (information technology) which has been exceedingly developed make it possible to utilize its application in broad fields as providing a convenient way to gather and to reuse information. As smart phones have been sporadic nowadays which boost increase of SNS in real-time making more dynamic, it is becoming more worthful as a marketing tool in the field of fashion area. In this study, we have explored some case studies in which they are actively using Facebook. We have selected 10 fashion brands to compare their activities in boards containing 'notice', 'like this', 'people talking about this' and 'event'. We also conduct the correlation analysis between the indicators above, using Spearman's rank correlation coefficient. As a consequence, we can confirm that 'notice' highly correlates with 'like this', but we cannot find any other correlations between the other factors. As a reasult, marketing in Facebook is more efficient communication way between the companies and customers than using other current mass media, it shows that SNS in fashion marketing could be an innovative solution to overcome current limitations caused probably by lack of communications.
\end{abstract}

Key Words : SNS, Fashion marketing, Facebook, Smart phone, Information processing

\section{1. 서론}

최근 IT 분야에서 최고의 화제가 되고 있는 분야 중 하나로 '빅 데이터'를 생각할 수 있다. 스마트 디바이스 의 확대와 융합 콘텐츠의 다양성, 소셜 네트워크 서비스
(SNS) 등의 출현은 새로운 형태와 방대한 양의 정보를 끊임없이 생산하고 있고 이는 정보의 생성, 이동, 가공, 소멸의 전 과정에서 생성되는 새로운 형태의 데이터 처 리기술을 요구하고 있다. 또 이를 활용하여 비즈니스의 경쟁력 강화를 위해 소비자 패턴을 추출하는 연구가 활

${ }^{*}$ Corresponding Author : Seongah Chin

Tel: +82-10-4641-0122 email: solideochin@gmail.com

접수일 12년 03월 07일수정일 (1차 12년 04월 13일, 2차 12년 04월 19일)

게재확정일 12 년 05 월 10 일 
발히 전개되고 있다. 기업은 빅 데이터가 갖는 핵심적인 정보를 분석하고 소비자의 성향을 파악하여 마케팅에 접 목을 시도하고 있다. 소비자는 기업이나 솔루션이 제공하 는 개인 성향에 맞는 프로그램을 스마트 디바이스 등을 통하여 구매와 상품정보에 대한 서비스를 편리하게 받을 수 있다. 근래 큰 이슈가 되고 있는 SNS도 '빅 데이터'의 하나로서 지속적인 사용자들의 증가로 인해 데이터의 크 기도 점점 거대해지고 있는 실정이다. 이용자들의 지속적 인 증가는 그 안에서의 새로운 커뮤니티의 증가세를 보 여주는 것이다. 이로 인해 새로운 공간에서 사람들 간 자 연스럽게 그룹이 생성된다.

Choi(2009)는 SNS의 사용은 브랜드와 고객 간의 관계 를 더 쉽게 이어주고 $\mathrm{CRM}$ (고객 관계 관리)까지 포함하 는 좋은 방법이 될 수 있다고 말하였는데[1], 이와 같은 새로운 커뮤니티의 등장은 마케팅의 영역을 확장할 수 있는 좋은 대상이 될 수 있다. 그러므로 SNS는 기업의 마 케팅 툴로 이용하기에 충분한 의의가 있는 것이다. Apple 사의 iPhone이 국내에 출시된 이후부터 스마트 폰이라는 또 하나의 새로운 패러다임의 기기가 급속도로 보급되기 시작하였다. 내 손안의 컴퓨터로 지칭되는 스마트 폰은 실시간 인터넷 접속을 통하여 정보의 수집, 가공, 유포를 상당히 용이하게 해준다. 한국 인터넷 진흥원(2011)에서 조사한 무선 인터넷 이용실태조사 보고서에 의하면 12 59세 인구의 10 명 중 4명이 스마트 기기(스마트 폰, 스마트 패드)를 이용하고 있다[2]. 또한, 한국 인터넷 진 흥원(2011)에서 조사한 스마트 폰 이용실태조사 보고서 와 무선 인터넷 이용실태조사 보고서에서는 12 59세 스 마트 폰 이용자 중 $87.1 \%$ 가 $\mathrm{SNS}$ 이용경험이 있었고 동 일 연령대에서 이동전화(스마트 폰 포함)의 전체 이용자 의 $16.9 \%$ 가 최근 일주일 이내에 SNS를 이용했다고 보고 하였다[3]. 제시한 보고서의 내용을 바탕으로 미루어 짐 작해 볼 때 앞으로 증가할 스마트 기기의 보급과 인프라 확산으로 SNS의 사용빈도는 더욱 증가할 것으로 예측되 며 마케팅 도구와 수익성 모델로서 SNS가 갖는 의미를 체계적으로 연구할 필요가 있을 것이다. 따라서 본 연구 에서는 패션 업체에 적용되고 있는 SNS 서비스의 사례와 형태를 분석하여 SNS 마케팅의 실체가 갖는 유의미적인 요소와 합리적인 서비스에 필요한 방향을 설정하고자 한 다. 특별히 SNS 중에서도 국내 Facebook 페이지를 이용 하여 마케팅을 하고 있는 10 개의 업체의 실증자료를 토 대로 사례연구를 수행하고자 한다. 현재 각 분야에서 $\mathrm{SNS}$ 를 이용하여 마케팅을 진행하고 있지만 본 연구진이 조사한 바로는 SNS를 이용한 패션 마케팅에 대한 분석적 인 연구를 찾기가 쉽지 않았기에 연구적 가치가 있다고 생각한다.

\section{2. 이론적 배경}

\subsection{SNS(Social Network Service)와 Facebook}

SNS(Social Network Service)란 인터넷상에서 친구, 동 료 등 지인과의 인간관계를 강화하거나 새로운 인맥을 형성함으로써 폭넓은 인적 네트워크를 형성할 수 있게 해주는 웹 서비스이다.

국립국어원에서 운영하는 우리말 다듬기(2010)는 이 러한 성격을 반영하여 '누리 소통망'이라는 말로 다듬어 서 표현하였다[4]. 현대적 의미의 소셜네트워크 시작은 1997년 미국의 sixdegrees.com이라는 웹페이지인데 현재 의 SNS와 유사한 서비스를 제공하면서 시작되었고 이것 을 토대로 마이스페이스, 페이스북, 트위터 서비스가 등 장하게 되었다[5]. 글로벌 미디어 리서치 조사기관 Universal Mccan(2010)에 의하면 전 세계 53 개국 37,600 명을 대상으로 응답자의 $47 \%$ 가 SNS 커뮤니티를 방문하 고 있다고 말하고 있고 현재 전 세계에서 이용자들은 계 속해서 증가하는 추세라고 보고하고 있다[6]. 국내에서는 2010년 이후로 알려지기 시작하면서 유저들의 수가 급격 히 증가하였는데 Park(2010)은 SNS를 사용하는 주된 이 유로 특정 그룹에 소속되어 정보를 얻고 동향을 확인할 수 있다는 점과 사람들과의 인적 네트워크를 통하여 소 통할 수 있고, 관계를 맺기가 쉽고 편리하기 때문이라고 설명하고 있다[7].

Facebook은 하버드 대학교의 학생이었던 마크 저커버 그가 2004년 2월 4일에 개설한 서비스로 13살 이상의 전 자 우편 주소를 가진 사용자라면 누구나 서비스를 이용 할 수 있는 대표적인 SNS 중의 하나이다. 기존 국내에서 개발된 싸이월드와 블로그와는 차별성을 두고 구글과 같 이 글로벌화를 무기로 전 세계의 이용자를 매료하여 최 근에 급격한 이용자의 증가세를 보여주고 있다. 기본적인 인터페이스는 게시물을 업데이트할 수 있는 '개인 담벼 락' 또는 커뮤니티 그룹인 ‘페이지’가 있고 각각의 게시 물과 페이지에는 사용자의 추천개념과 유사한 'like'와 'like this'가 존재한다. 특별히 '페이지'에서는 'people talking about this'라는 수치가 있는데 당일을 제외한 지 난 일주일 동안 '페이지' 안에서 있었던 활동지표를 보여 주는 수치로 값이 클수록 사람들의 관심과 활동이 많음 을 시사한다. Socialbakers의 SNS 통계자료인 Facebook Statistic(2012)에 의하면 2012년 1월 12일을 기준으로 전 세계적으로 $785,300,320$ 명의 사람이 페이스북을 이용하 고 있다고 조사하였는데[8], 이것은 전 세계 인구의 약 $10 \%$ 가 페이스북을 이용하고 있다는 사실을 보여주고 있 으며 그 안에는 약 $1,800,000$ 개의 방대한 커뮤니티가 존 
재하고 있다. 동일 시간 국내 페이스북 유저들은 $5,355,880$ 명으로 조사되었고 10 대, 20 대, 30 대가 $83 \%$ 를 차지하고 있을 만큼 젊은 층이 활발한 활동을 하고 있다.

\subsection{SNS 마케팅}

SNS 마케팅은 트위터, 페이스북 등 SNS를 이용한 차 세대 마케팅 기법의 하나이다. Choi와 Do(2011)는 SNS 가 가지고 있는 바이럴 마케팅 속성은 제품의 평가를 실 시간으로 빠르게 전파하는 유용한 도구로 활용되기에 충 분하다고 말했다[9]. 실제로 바이럴 마케팅 효과와 적은 운영비용을 장점으로 다수 기업이 자사의 마케팅 도구로 $\mathrm{SNS}$ 를 이용하고 있는데 근래에는 스마트폰 보급의 확산 으로 실시간으로 SNS를 이용할 수 있다는 이점까지 가해 져 전 세계적으로 기업들의 SNS 운영이 빠르게 확산 되 는 추세이다. 실제로 포천 100 대 기업 중 한 개 이상 소 셜 미디어 채널을 운영하는 기업이 전체 $79 \%$ 에 달하는 만큼 기업들은 SNS의 운영을 중요하게 인지하고 있다 [10]. 외국에서는 이미 많은 이용자를 확보하여 SNS 마 케팅을 적극 진행하고 있고 실례로 세계적인 기업인 스 타벅스는 고객 중심의 SNS 마케팅을 적용하여 성공사례 를 보여주었다[11]. 그밖에 국내 브랜드인 '버커루 진'과 ‘코오롱 스포츠'는 트위터를 사용하여 활발하게 마케팅 을 전개하고 있으며 각각 브랜드 특성에 맞게 감성적 마 케팅과 소비자들의 필요를 제공함으로써 사람들의 관심 을 끌고 있다[12].

국내 기존 SNS 마케팅은 트위터를 이용한 방법이 대 부분이었으나 근래에는 사용자들이 급격하게 증가하고 있는 페이스북으로 방향이 바뀌고 있다. 이를 토대로 국 내에서도 Facebook을 이용한 마케팅을 적극 이용하는 추 세이다.

\section{3. 연구 방법}

소셜 미디어 랭크 사이트와 페이스 북 페이지에 랭크 되어 있는 패션 관련 업체의 페이스북 페이지를 참고하 여 현재(2012년 1월 10일) 기준으로 'like this' 수치가 높 은 순서로 10 개의 브랜드를 추출하였다. 페이지의 활동 성을 보여주는 지표인 '게시글', 'like this', 'people talking about this' 수치를 페이지별로 개수하여 비교 연구를 수 행하였다. 월별 게시글의 변화량 추이를 그래프로 변환하 여 의미를 해석하였고, 위의 세 가지 지표들 사이의 연관 성을 확인하기 위하여 Spearman 순위 상관계수를 이용한 상관분석을 실행하였다. 분석 도구로는 SPSS WIN 12.0
을 사용하였다.

선행된 연구를 바탕으로 페이지 활동성이 높은 3 개의 페이지를 추출하여 2012년 1월 한 달 동안 페이지 내의 세부적인 정보(게시글, like, reply의 내용과 이벤트의 종 류)를 조사한 후, 활동성 있는 페이스북 페이지의 마케팅 사례를 집중적으로 연구하였다.

10 개의 브랜드 중 외국 브랜드가 과반수인 7 개를 차지 하였고 분류별로는 스포츠 3 개, 유니섹스 3 개, 여성 캐주 얼 1 개, 운동화와 여성구두 3 개, 패션 몰 1 개였다.

표 1은 소셜 랭크 사이트[13]에서 제공되는 자료로 최 근 3 주간 페이지의 'like this'가 높은 순서로 1 위부터 10 위까지의 페이지를 정리한 것이다.

[표 1] 1월 3일 24일 3주간 페이지 'like this' 순위표 [Table 1] The 'like this' rank chart during three weeks

\begin{tabular}{|l|c|c|c|}
\hline \hline \multirow{2}{*}{ Brand Ranking } & $1 / 11$ & $1 / 18$ & $1 / 25$ \\
\cline { 2 - 4 } & Like this & Like this & Like this \\
\hline 1. Nike Store & 46,382 & 46,655 & 47,335 \\
\hline 2. HEAD Korea & 44,596 & 44,711 & 44,884 \\
\hline 3. Uniqlo Korea & 39,261 & 39,466 & 39,847 \\
\hline 4. customellow & 24,130 & 24,196 & 24,363 \\
\hline 5. ABC Mart Korea & 19,865 & 20,143 & 20,544 \\
\hline 6. Nike Running Korea & 11,639 & 11,668 & 11,720 \\
\hline 7. Perche Korea & 11,159 & 11,155 & 11,157 \\
\hline 8. Doota & 10,259 & 10,247 & 10,259 \\
\hline 9. QUA & 9,072 & 9,063 & 9,039 \\
\hline 10.Lacoste L!VE Korea & 7,098 & 7,125 & 7,180 \\
\hline
\end{tabular}

\section{4. 연구내용}

\section{1 각 브랜드의 게시글 빈도를 이용한 비교 연구}

2012년 1월 게시글 빈도만으로는 연구 데이터의 크기 가 미미하다고 판단하여 2011년 3월에 개시한 페이지를 기준으로 12 월까지 월별로 페이지 관리자와 사용자가 작 성한 글을 각각 개수하였고 그 내용은 표 2로 정리 하였다.

표 2에서 발견된 특이점은 과반수의 페이지에서 사용 자들의 게시 글을 확인할 수 없었다. 사용자의 게시글을 발견할 수 없었던 여섯 개의 페이지 중 네 곳은 사용자가 글을 게시할 수는 있었지만, 관리자는 게시물에 'reply'만 남긴 후 담벼락에서 글을 블라인드하고 있었다. 나머지 두 곳은 사용자가 글을 게시할 수 있는 권한이 없었다. 
[표 2] 페이지에 게시된 글의 빈도(1)

[Table 2] The frequency of reports (1)

\begin{tabular}{|l|c|c|c|}
\hline \hline \multirow{2}{*}{ Brand Rankings } & \multicolumn{2}{|c|}{$\begin{array}{c}\text { The frequency of } \\
\text { reports }\end{array}$} & \multirow{2}{*}{$\begin{array}{c}\text { Total } \\
(\mathrm{a}+\mathrm{b})\end{array}$} \\
\cline { 2 - 3 } & User(a) & Admin(b) & \\
\hline 1. Nike Store & 1,060 & 612 & 1,672 \\
\hline 2. HEAD Korea & 337 & 158 & 495 \\
\hline 3. Uniqlo Korea &. & 597 & 597 \\
\hline 4. customellow & 557 & 597 & 1,154 \\
\hline 5. ABC Mart Korea &. & 765 & 765 \\
\hline 6. Nike Running Korea &. & 810 & 810 \\
\hline 7. Perche Korea &. & 192 & 192 \\
\hline 8. Doota &. & 1,150 & 1,150 \\
\hline 9. QUA & 238 & 644 & 882 \\
\hline 10.Lacoste L!VE Korea &. & 151 & 151 \\
\hline
\end{tabular}

표 2 의 자료를 이용하여 비교 분석을 하기에는 기준이 맞지 않아 정량적 기준이 되지 못하였기에 사용자와 관 리자 모두가 글을 게시할 수 있었던 네 개의 페이지만 따 로 추출한 후 사용자와 관리자가 게시한 글의 비율을 추 가하여 표 3으로 요약하였다.

표 3의 내용으로 확인할 수 있듯이 대체로 페이지의 'like this'의 수가 많을수록 사용자가 글을 게재하는 비율 이 관리자가 글을 게재하는 비율보다 높은 것을 볼 수 있 었다. 좀 더 구체적인 연구를 위해 월별로 사용자들이 페 이지에 게시한 글을 월별로 개수하여 변화 추이를 비교 해본 결과 7 8월과 11 12월경에 급격한 게시글의 증가 를 확인할 수 있었고 월별 변화 추이는 그림 1 과 같이 조 사되었다.

그림 1 을 보면 각각의 페이지별로 여름과 겨울에 근접 했을 때 그래프의 정점을 확인할 수가 있었는데 이것을 통해서 이 기간에 게시물이 양이 급격히 많아졌다는 것 을 알 수 있었다. 특별히 게시물 증가의 주된 이유를 파 악하기 위하여 페이지별로 게시글 증가 시점의 내용을
조사해 보았다. 1 번 브랜드는 소장가치가 있는 자사의 특 정 제품을 한정된 수량으로 선착순으로 판매하고 있었는 데 이벤트 진행에 대한 소비자의 불만사항에 대한 글이 대부분을 차지하고 있었다. 2 번 페이지의 경우는 사용자 들이 이벤트 참여를 위하여 페이지를 'like this'하고 관리 자에게 인증을 받기 위한 게시글이었다. 4번과 9번 브랜 드의 경우도 2 번 브랜드와 유사하게 이벤트 참여를 위하 여 관리자에게 인증을 받기 위한 게시글이었다. 결과적으 로 이벤트가 끝난 직후의 게시율이 급격히 떨어지는 것 을 그래프로 확인할 수 있었는데 이는 이벤트가 일시적 으로 사용자들의 참여를 유도할 수 있었으나 지속적인 활동으로는 연결하지 못함을 인지시켜 주는 것이었다.

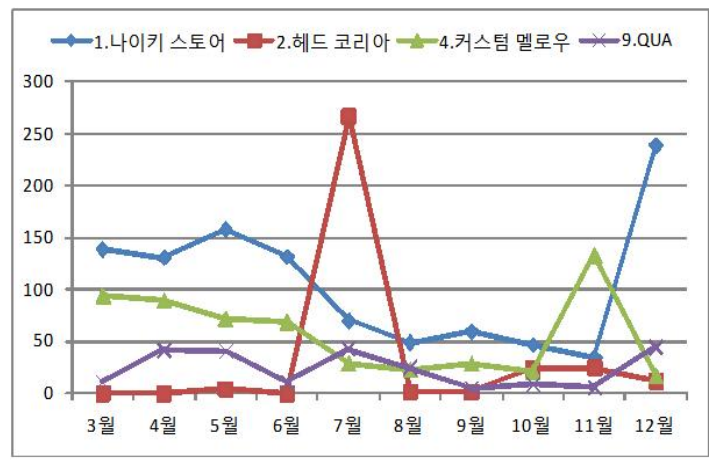

[그림 1] 사용자의 월별 게시글의 증가량 추이

[Fig. 1] The change rates of monthly reports from users

표 4는 2012년 1월의 자료를 토대로 위의 두 가지 지 표를 조사하여 정리한 것이고 표 5는 'people talking about this'를 'like this'로 나눈 후 백분율로 환산하여 이 것을 'activity rate'로 명명하여 새롭게 정리한 표이다. 표 6 을 참고했을 때 3 주 동안 조사한 'activity rate'의 가장 높은 수치는 약 $8.25(\%)$ 로 $10 \%$ 가 안 되는 것으로 조사되 었고 한 곳을 제외한 아홉 곳의 3 주 평균은 $5 \%$ 가 채 되 지 않았다.

[표 3] 페이지에 게시된 글의 빈도(2)

[Table 3] The frequency of reports (2)

\begin{tabular}{|l|c|c|c|c|c|}
\hline \hline \multirow{2}{*}{ Brand rankings } & \multicolumn{2}{|c|}{ The frequency of reports } & \multirow{2}{*}{$\begin{array}{c}\text { Total } \\
\text { (c) }\end{array}$} & \multicolumn{2}{c|}{ Report rate(\%) } \\
\cline { 2 - 3 } \cline { 5 - 6 } & User(a) & Admin(b) & User (a/c*100) & Admin (b/c*100) \\
\hline 1. Nike Store & 1,060 & 612 & 1,672 & $63.40 \%$ & $36.60 \%$ \\
\hline 2. HEAD Korea & 337 & 158 & 495 & $68.10 \%$ & $31.90 \%$ \\
\hline 9. customellow & 557 & 597 & 1,154 & $48.27 \%$ & $51.73 \%$ \\
\hline
\end{tabular}


[표 4] 활동비율

[Table 4] The activity rate

\begin{tabular}{|l|c|c|c|c|c|c|}
\hline \hline \multirow{2}{*}{ Brand rankings } & \multicolumn{2}{|c|}{$1 / 11$} & \multicolumn{2}{c|}{$1 / 18$} \\
\cline { 2 - 7 } & $\begin{array}{c}\text { Like this } \\
\text { (a) }\end{array}$ & $\begin{array}{c}\text { People talking } \\
\text { about this(b) }\end{array}$ & $\begin{array}{c}\text { Like this } \\
\text { (a) }\end{array}$ & $\begin{array}{c}\text { People talking } \\
\text { about this(b) }\end{array}$ & $\begin{array}{c}\text { Like this } \\
\text { (a) }\end{array}$ & $\begin{array}{c}\text { People talking } \\
\text { about this(b) }\end{array}$ \\
\hline 1. Nike Store & 46,382 & 1,235 & 46,655 & 979 & 47,335 & 1,674 \\
\hline 2. HEADKorea & 44,596 & 1,316 & 44,711 & 312 & 44,884 & 336 \\
\hline 3. Uniqlo Korea & 39,261 & 1,395 & 39,466 & 1,357 & 39,847 & 1,087 \\
\hline 4. customellow & 24,130 & 350 & 24,196 & 459 & 24,363 & 486 \\
\hline 5. ABC Mart Korea & 19,865 & 761 & 20,143 & 797 & 20,544 & 555 \\
\hline 6. Nike Running Korea & 11,639 & 181 & 11,668 & 216 & 11,720 & 392 \\
\hline 7. Perche Korea & 11,159 & 656 & 11,155 & 876 & 11,157 & 921 \\
\hline 8. Doota & 10,259 & 465 & 10,247 & 535 & 10,259 & 493 \\
\hline 9. QUA & 9,072 & 147 & 9,063 & 274 & 9,039 & 199 \\
\hline 10. Lacoste L!VE Korea & 7,098 & 369 & 7,125 & 82 & 7,180 & 142 \\
\hline
\end{tabular}

[표 5] 3주간 활동 비율 평균

[Table 5] The average of activity rate during three weeks

\begin{tabular}{|c|c|c|c|c|}
\hline \multirow[b]{2}{*}{ Brand rankings } & $1 / 11$ & $1 / 18$ & $1 / 25$ & \multirow{2}{*}{$\begin{array}{c}\text { Average } \\
\text { of activity } \\
\text { rate }(\%)\end{array}$} \\
\hline & $\begin{array}{c}\mathrm{c} \\
(\%)\end{array}$ & $\begin{array}{c}\mathrm{c} \\
(\%)\end{array}$ & $\begin{array}{c}\mathrm{c} \\
(\%)\end{array}$ & \\
\hline 1. Nike Store & 2.66 & 2.10 & 3.54 & 2.77 \\
\hline 2. HEAD Korea & 2.95 & 0.70 & 0.75 & 1.47 \\
\hline 3. Uniqlo Korea & 3.55 & 3.44 & 2.73 & 3.24 \\
\hline 4. customellow & 1.45 & 1.90 & 1.99 & 1.78 \\
\hline 5. ABC Mart Korea & 3.83 & 3.96 & 2.70 & 3.50 \\
\hline $\begin{array}{l}\text { 6. Nike Running } \\
\text { Korea }\end{array}$ & 1.56 & 1.85 & 3.34 & 2.25 \\
\hline 7. Perche Korea & 5.88 & 7.85 & 8.25 & 7.33 \\
\hline 8. Doota & 4.53 & 5.22 & 4.80 & 4.85 \\
\hline 9. QUA & 1.62 & 3.02 & 2.20 & 2.28 \\
\hline $\begin{array}{l}\text { 10. Lacoste L!VE } \\
\text { Korea }\end{array}$ & 5.20 & 1.15 & 1.98 & 2.78 \\
\hline \multicolumn{4}{|c|}{ Total Average } & 3.23 \\
\hline
\end{tabular}

$*$ c(activity rate $)=\mathrm{b} / \mathrm{a} * 100(\%)$

좀 더 세밀한 연구를 위해 표 4 와 표 5 의 내용을 토대 로 'like this'와 'people talking about this', 'Average of activity rate'가 지표 간 상호 연관성이 있는지 확인하기 위하여 상관분석을 실행 하였다. 분석결과 'like this'와 'people talking about this' 요인 사이에는 p-value 0.016,
상관계수 0.733 으로 유의수준을 만족하여 높은 양의 상 관관계가 있음을 확인할 수 있었지만 'like this', 'Average of activity rate' 요인과의 관계에서는 p-value 0.310 , 상관계수 0.358 로 유의수준 $\mathrm{p}<0.05$ 를 만족하지 못 하였기에 상관성을 확인할 수 없었다.

결과적으로 'like this'의 수치와 'people talking about this'는 서로 양의 비례관계가 성립되었지만 1 인당 활동 비율인 'Average of activity rate'와는 특별한 연관성을 설 명할 수가 없었다. 이는 단순히 페이지의 'like this'가 높 다고 해서 페이지의 활동성이 높다고 말할 수 없는 결과 였다.

\section{2 활동성이 높은 상위 3 개 페이지 사례연구}

상위 연구를 토대로 1월 3주의 'Average of activity rate'가 높았던 'Perche Korea'와 'people talking about this'가 높았던 'Nike Korea'와 'Uniqlo Korea'를 활동성 이 높은 상위 3 개 페이지로 선정하였다. 특별히 'people talking about this' 지표에서 두 곳을 선정한 근거는 'people talking about this'의 상위 1,2 위 수치 차이가 표 5 의 'Average of activity rate' 상위 1,2 위의 수치 차이보 다 그 차이가 미미했기에 'people talking about this' 지표 에서 2곳을 추출하게 되었다.

[표 6] 활동성이 높은 상위 페이지 게시글 당 평균 참여도 [Table 6] The average of participation

\begin{tabular}{|l|c|c|c|c|}
\hline \hline \multicolumn{1}{|c|}{ Brand rankings } & Report(a) & Like(b) & Reply(c) & $\begin{array}{c}\text { participation } \\
(\mathrm{d}=\mathrm{a}+\mathrm{b}+\mathrm{c})\end{array}$ \\
\hline Nike Store & 48 & 3192 & 618 & 3,858 \\
\hline Uniqlo Korea & 35 & 4352 & 697 & 5,084 \\
\hline PERCHE Korea & 32 & 2918 & 1691 & 4,641 \\
\hline
\end{tabular}


조사기간은 2012년 1월 7일 24일이었지만 1월 1일 부터 조사해도 무방하다고 판단하였고 정확한 사례 연구 를 위하여 조사기간 내에 '게시된 글'과 'like', 'reply'의 수를 개수하여 표 6에 정리하였다. 세 곳 중 나이키 스토 어만 사용자들이 글을 올릴 수 있었는데 게시글의 숫자 가 적어 그 영향이 미미하고 비교 기준에 맞지 않으므로 개수할 때는 제외하였다.

Nike Store는 제품에 관한 게시글에 많은 호응을 보였 었고 페이지 사용자들 간에 소통이 활발히 일어나고 있 었다. 미루어 짐작해 보았을 때 마니아층을 포함한 품 이 용자가 상당수 존재하는 것으로 추측되었다. Uniqlo Korea도 Nike Store와 비슷하게 게시글 대부분은 제품 소 개와 온, 오프라인 프로모션에 관한 글이었는데 사용자들 의 'reply' 내용을 보면 브랜드에 대해 긍정적인 이미지를 가지고 있는 소비자의 제품에 대한 의견과 선호도 내용 이 다수였다. 두 브랜드는 대체로 페이지를 통하여 신상 품 정보와 입고 정보를 꾸준히 게시하여 사용자들에의 필요를 만족하게 하고 있었다. 특별히 Perche Korea는 Nike Store와 Uniqlo Korea비해 페이지 'like this'의 수치 가 현저히 차이가 남에도 게시글 당 'reply' 비율이 가장 높게 관찰되었는데(2011. 1. 24일 기준, 각 페이지의 'like this'의 수, Nike Store: 1,651/ Uniqlo Korea: 39,797/ Perche Korea: 11,159$)$ 게시글의 내용을 조사해보니 Prototype 상 품에 대한 사용자들의 의견을 구두 디자인에 반영하겠다 는 게시물에 많은 사람이 호응하고 있었다. 또, 게시된 전 체 글 중에서 이와 같은 성격의 글의 비율이 $43.75 \%$ 를 차지하고 있었고 평균 'reply'/like this' 100.93개/63.8개 로 다른 종류 게시물의 평균인 83.61/44.28에 비해 반응 을 많이 하는 것으로 나타났다.

\section{5. 결론 및 제언}

본 연구는 최근 마케팅 트렌드로 급부상하고 있는 SNS 서비스 중 페이스북 페이지 마케팅 사례를 패션업체 중심으로 조사하여 패션업체의 SNS 마케팅 사례를 살펴 보고자 하였다. 연구결과와 제언을 다음과 같이 제시하고 자 한다.

첫째, 사용자의 게시글 참여의 통제는 SNS와 패션분 야에서 중요한 상호 커뮤니케이션 효과를 감소시키는 요 인이 될 수 있는 것으로 볼 수 있었다. 일부 페이지는 관 리자가 게시된 글에 'reply'만 남겨주고 담벼락 상에서는 블라인드를 하고 있었다. 이 경우 사용자가 페이지에서 볼 수 있는 주된 내용은 관리자의 게시글로 제한되는데 사용자는 게시글의 'reply' 정도만 참여할 수 있었기에 활
동성 있는 SNS의 가장 큰 특징이자 장점인 상호 커뮤니 케이션 활성화에 저해 요소가 될 수도 있다고 생각된다. 특별히 패션분야에서 제품에 대한 사람들의 의견 공유는 중요한 요소인데 소통을 통제하는 것은 부정적인 결과를 낳을 수도 있다고 판단된다.

둘째, 단순 이벤트만으로는 페이지 활성화의 한계가 있음을 볼 수 있었다. 브랜드별로 매월 게시글 변화량을 분석한 결과 여름(7 8월)과 겨울(11 12월)에 게시글의 수가 최고점에 있음을 알 수 있었다. 시기적으로 신상품 홍보와 구매 욕구를 자극하기 위한 이벤트가 전개되었고 페이지에 사람들을 유치하기 위한 이벤트도 발견되었다.

게시글의 내용을 구체적으로 조사해 본 결과 한 곳은 이벤트 과정 중 생기는 문제 때문에 사용자들의 불만이 포함된 게시물이 대부분이었고 나머지 세 곳은 이벤트에 참여하기 위해 페이지를 'like this' 한 후 관리자가 확인 할 수 있도록 인증 게시글을 남긴 것이었다. 하지만 이벤 트가 있었을 때 게시글의 수가 정점을 찍고 나서 게시율 이 급격히 떨어지는 것을 볼 수 있었는데 단순히 한시적 인 이벤트만으로는 사용자들의 참여를 지속시키기는 쉽 지 않음을 나타내고 있었다. 이벤트 이후의 사후 관리의 중요성을 알 수 있었고 즉각적인 사용자들의 불만사항 탓에 브랜드와 페이지에 부정적인 이미지를 남길 수 있 기에 이벤트 계획과 진행에 대해 브랜드들이 많은 노력 과 연구의 필요성을 인지할 수 있었다.

셋째, 참여도를 높이기 위해서는 SNS와 패션의 성격 을 접목한 특별한 이벤트와 운영이 필요하다고 사료된다. 대부분 페이지에서 이벤트에 참가하려면 'like this'나 게 시글을 공유해야 참여할 수 있었는데 이것은 이벤트를 통해서 페이지의 팬을 유치하고, 사용자들에 의해 바이럴 마케팅 효과를 기대하는 것으로 보인다. 하지만 이런 이 벤트에 의한 'like this'보다도 사용자들이 자발적으로 참 여할 수 있는 유용한 콘텐츠를 제공하고 단순한 이벤트 를 벗어나서 'ABC Mart Korea'의 유니세프 기부와 같은 긍정적인 이벤트, 또는 'PERCHE Korea'와 같이 특정 시 간에만 참여할 수 있고 경품으로 자사 제품을 증정하는 방식의 색다른 참여 이벤트의 제안이 더 필요하다고 사 료된다. 활성화 정도가 높은 세 곳의 페이지는 기본적으 로 페이지의 'like this'가 높았는데 정보(신상품, 세일 정 보)를 지속해서 게시하고 이벤트를 적절하게 진행하고 있었다. 이것을 통하여 사용자들이 페이지에 관심을 끌게 하고 페이지 내에서 다른 사용자들과 소통할 수 있는 공 감대를 형성시켜 주고 있었다. 특히 'PERCHE Korea'가 페이지 'like this' 수치에 비해 높은 참여율을 보이는 큰 이유의 하나는 제품을 출시할 때 소비자의 의견을 디자 인에 참고하는 것이 중요한 요인으로 판단되었다. 이것은 
페이지 내에서 더욱 직접 사용자의 의견을 반영하겠다는 것이기에 사용자들에게 참여를 동기부여 할 수 있었을 것이다.

넷째, 'like this'의 수와 페이지의 활동성과는 비례하 지 않는 것으로 판단되었다. 'like this'와 'people talking about this', '활동비율'의 상관분석을 실행한 결과 'like this'와 'people talking about this'와는 높은 양의 상관관 계를 보였지만 'like this'와 '활동비율'과의 관계에서는 관계성을 확인할 수 없었다. 표면적으로 봤을 때는 'like this'의 수가 증가하면 ‘people talking about this'도 증가 하기 때문에 'like this'를 높이는 것이 중요해 보이지만 1 인당 활동비율인 'Average of activity rate'와는 관계성을 볼 수 없기에 단순히 'like this'를 높이는 것으로는 'Average of activity rate'의 상승효과를 기대하기는 어려 운 것으로 판단되었다. 이것은 페이지를 'like this' 한 사 람 중 대다수는 페이지 활동에 특별히 참여하지 않는 것 으로도 해석될 수 있다. 페이지를 이용하여 마케팅을 할 때 실수하기 쉬운 잘 못된 점의 하나는 단순히 'like this' 만 늘리는 것인데 페이지 운영자들은 사람들과의 소통과 참여를 일어날 수 있도록 기반을 마련하는 것이 사람들 을 유치하는 것보다 더 중요한 요인임을 인지해야 할 것 이다.

본 연구는 기존 페이스북을 이용한 마케팅을 분석한 연구사례가 미미했었기에 연구의 의의를 지니고 있지만, 다음과 같은 한계점을 가지고 있다. 연구에서 중요하게 지목하였던 'people talking about this' 지표는 페이지의 활성화 상태를 가장 잘 알려주는 지표이지만 실질적으로 페이지에서 확인할 수 있는 수치들은 '게시글', 'like', 'reply', ‘공유', ‘태그' 등만 있기 때문에 완벽하게 연구에 반영하지 못하는 한계점을 지니고 있다. 그러므로 추후 사례연구에서는 좀 더 정확한 자료에 의해 대상을 추출 해야 할 필요가 있다. 하지만 페이지 관리자는 페이스북 상에서 방문자의 수, 성별, 트래픽 시간, 등 구체적이고 많은 정보를 수집할 수 있기 때문에 자사의 브랜드를 더 효과적으로 연구할 수 있을 것이다.

시간이 지날수록 SNS 유저들의 증가로 인하여 SNS 마케팅의 효용성은 더 커질 것이다. SNS 마케팅의 핵심 은 소통이다. 소통은 곧 공감과 연결될 수 있다. 그리고 이것은 소비자와의 관계의 질의 향상을 의미한다. 소통을 위해서는 소통할 수 있는 그 무엇이 필요하고 그것은 좋 은 정보가 될 수 있고 브랜드가 될 수도 있지만 가장 중 요한 것은 그 중심에 실체가 있어야 하고 가치와 진정성 이 포함되어야 할 것이다[14].

특별히 패션분야의 특성을 고려하여 소비자와 브랜드 와의 소통을 원활하게 만든다면 이것은 실시간으로 다수
사용자에게 빠른 속도로 전달되기에 파급효과는 배가될 것이다. 그렇기에 페이지 내에서 소통과 자유의 속성이 살아난다면 더 큰 이윤과 사용자의 마음을 동시에 잡을 수 있을 것이다. 페이스북 페이지를 운영하는 패션 업체 들은 소비자 만족과 소비자와의 소통의 방법을 연구하여 앞으로의 방향을 준비해야 할 것이다.

\section{Reference}

[1] Jason. Choi, 'SNS' a New Focus of Communication Paradigm. Cheil Magazine, 2009.

[2] Korea Internet \& Security Agency, The Summary Report of Actual Condition Survey in Wireless Internet Usage. 2011, Korea Internet \& Security Agency, 2011.

[3] Korea Internet \& Security Agency, The Summary Report of Actual Condition Survey in Smartphone Usage for the First Half of the Year. 2011, Korea Internet \& Security Agency, 2011.

[4] The National Institute of The Korean Language, 'Nuri Sotongmang' is changed to The Soclal Network Service, The National Institute of The Korean Language, 2010.

[5] J. M. Im, and J. J. Im, Trans., "The facebook effect : The Inside Story of the Company That Is Connecting the World", Seoul: Acorn, pp.103-104, 2011.

[6] Universal Mccan, Wave 5 - The Socialisation of brands, Universal Mccan, 2010.

[7] K. Y. Park, The Generation of Connection-Tech's Player, Cheil Magazine, 2010.

[8] Socialbakers, "Socialbakers Facebook Statistics", Socialbakers, 2012, 1. 12, http://www.socialbakers.com/facebook-statistics

[9] G. W. Choi and S. H. Do, Trans., "Facebook marketing", Seoul: Spectrum Books, pp.75-78, 2011.

[10] Y. K. Seo, and J. W. Kim, and S. Y. Jo, "The Business Successful Strategies for the SNS Introduction", Proceeding of the Korea Society of Management Information System, Fall Conference, Vol. 2011, No. 1, pp.6-14, Fall, 2011.

[11] MezzoMedia Newsletter, The Case Analysis of SNS Marketing -Starbucks-, MezzoMedia, 2010

[12] Y. S. Sun, et. al., "Case Study of SNS (Social Networks Service) Application on Fashion Corporate -Focused on Twitter-", Journal of Fashion Business, Vol. 15, No. 1, pp.158-170, 2011.

[13] http://www.socialdigm.com

[14] H. J. Seo, The Victory of Authenticity and Story, Cheil Magazine, 2010. 


\section{김 태 진(Taejin Kim)}

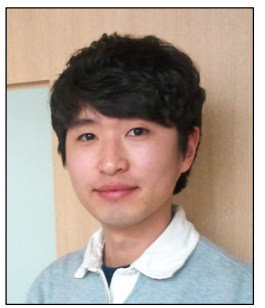

- 2011년 2월 : 성결대학교 멀티미 디어공학부(학사)

- 2011년 8월 현재 : 성결대학 교 멀티미디어공학부 Xicom Lab. 연구원

<관심분야>

IT, 모바일, 정보가공, 통계분석, 마케팅

\section{[정회원]}

진 성 아(Seongah Chin)

[정회원]

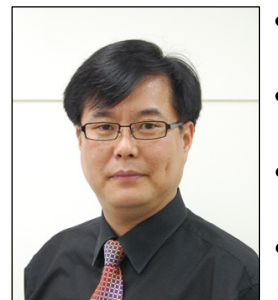

- 1991년 2월 : 전북대학교 수학과 (학사)

- 1993년 2월 : 전북대학교 대학원 전자계산학과 (석사)

- 1999년 12월 : Stevens Institute of Technology, (박사)

2000년 6월 2001년 2월 : 서 강대학교 영상대학원 연구교수

- 2001년 3월 현재 : 성결대학교 멀티미디어공학부 교 수, Xicom Lab. 디렉터

<관심분야>

시각정보처리, 얼굴모델링, $\mathrm{BCI}$, 가상현실, 정보가공 